\title{
A CONCEPTUAL FRAMEWORK OF PRODUCT-SERVICE SYSTEMS DESIGN FOR SUSTAINABILITY TRANSITIONS
}

\author{
Y. Mitake ${ }^{凶}$, K. Hiramitsu, A. Nagayama, N. Muraoka, M. Sholihah and Y. Shimomura \\ Tokyo Metropolitan University, Japan \\ $\triangle$ mitake-yuya@ed.tmu.ac.jp
}

\begin{abstract}
Product-service systems (PSSs) are regarded as one of the promising ways to contribute to a sustainable society. Despite the well-developed knowledge, PSS design lack of long-term perspective to treat related changes and uncertainties. To address this issue, this paper proposes a conceptual framework of sustainable PSS design for sustainability transition by integrating insight from design approach for system innovation and transition. Applicability of the proposed framework is illustrated through application to example of PSS development project for wildlife nuisance in a suburban city.
\end{abstract}

Keywords: sustainability, sustainable design, product-service systems (PSS), social innovation

\section{Introduction}

Currently, there are strong demands to address urgent sustainability challenges caused by environmental pollution and resource consumption with poor planning due to modern mass production and the mass consumption economy. One promising way to address these challenges is the development of productservice systems (PSSs), which fundamentally change the traditional production and consumption model through highly integrated products, services and supporting networks (Mont, 2002; Cavalieri and Pezzotta, 2012; Vezzoli et al., 2016). A PSS does not only focus on the profits gained from the sale of products, but it also improves the eco-efficiency of resources and builds long-term relationships with customers by delivering services and supporting them appropriately throughout the product life cycle (Mont, 2002). In other words, the PSS approach is in the economic and competitive interest of providers to foster continuous innovation in reducing environmental impact and improving social equity and cohesion (Vezzoli et al., 2016). To realize the above benefits of PSS, there are methodologies to design PSS developed across several motivations (Cavalieri and Pezzotta, 2012; Vasantha et al., 2012). These methodologies can assist designers in each development stage (e.g. requirement management, concept development, evaluation, implementation...).

Despite the well-developed knowledge, several scientific reports pointed out limitations related to PSS design. In particular, Vasantha et al. (2012) reported a lack of long-term perspective for PSS to treat related risks and uncertainties. The main root cause of this issue is the PSS design research mainly focuses on the beginning of life (design and realization) (Cavalieri and Pezzotta, 2012). To accommodate unpredictable uncertainty of environment surrounding PSS and itself (change in customer requirement and expectations for PSS, unexpected interaction via the network, technological 
progress, intentional attacks from outside etc..), it is necessary to design adaptive PSS structure by anticipating any changes and risks in the early design stages.

Against the above background, this paper aims to develop a conceptual framework for sustainable PSS complementing long-term perspective deal with uncertainties related to PSS and its surrounding environment by integrating knowledge from emerging design approach for system innovations and transitions to sustainability, or shortly, sustainability transitions (Loorbach, 2010; Gaziulusoy and Öztekin, 2019). This emergent design approach can provide a complementary long-term and adaptive perspective to design sustainable PSS.

The rest of paper is as follows. Section 2 presents a motivation and research method of this study. Section 3 provides a summary of relevant literature and key insights upon which the conceptual framework is developed. Section 4 proposes a conceptual framework of sustainable PSS design for sustainability transition by integrating the insight explained in Section 3. The proposed framework is applied to the example of PSS development in Section 5. Then, this paper is finalized with Section 6.

\section{The motivation for multidisciplinary research in PSS}

In the current society with the increasing complexity and uncertainty, design, technology and elsewhere have to face and deal with "messy problematic situations." (Rittel and Webber, 1973; Cross, 2001). The integration of several disciplines is one of the ways to address such a wicked problem in the current sustainability paradigm (Rittel and Webber, 1973; Ledford, 2015). In terms of PSS research field, some studies noticed the need for multi- and interdisciplinary research to tackle design in the sustainability paradigm (Sakao and Shimomura, 2007; Vasantha et al., 2012; Baines et al., 2017; Brambila-Macias et al., 2018). Designing a PSS is a multidimensional activity that requires interaction between the designer, social actors (including policymakers, governmental agencies, NGOs and marketing) and technological artefacts producer (Morelli, 2003; Ceschin, 2013).

Design science research, which roots in engineering design and information systems, can be adopted as a research methodology that reinforces an approach addressing the above need (Hevner et al., 2004). This research therefore focuses on understanding the context of complex phenomena then creating and evaluating artefacts that solve the complex problems. This research comprises activities focused on building and applying new artefacts and evaluating the created artefacts. To improve the robustness of this study, the research was built upon a design science research approach. According to the design science research, this research was conducted in three main stages: (1) conceptual framework development of design artefacts, (2) application of the design artefacts, and (3) evaluation of the developed design artefacts. Specifically, this paper concentrates on stage (1) conceptual framework development of design artefacts. This paper develops a conceptual framework of sustainable PSS design for sustainability transition based on a review of the literature on PSS design and design for sustainability transitions (Section 3). The analysis result that provides the theoretical foundations for the framework is presented in section 4.

\section{Theoretical foundations: insight from literature}

In order to develop conceptual framework, this paper makes an initial theoretical foundation by integrating relevant insight from PSS design and design for sustainability transitions. The following subsection presents a summary of relevant literature and key insights.

\subsection{Existing PSS design approaches}

In the design field, the methods, guidelines and operational tools for PSS design are proposed across authors' views, depending on their definitions of PSS and specific objectives (Annarelli et al., 2016; Morelli, 2006; Vasantha et al., 2012). PSS design focuses on integrating business models, products and services together throughout the life cycle stages, creating innovative value addition for the system (Vasantha et al., 2012). Extant PSS design process models mainly covered the beginning of fife (BoL), which composed of requirement management, concept development and evaluation, design embodiment and evaluation, detailed design and test (Cavalieri and Pezzotta, 2012; Vasantha et al., 2012). 
At the beginning of PSS design research, Morelli (2003) started to argue about the design process for the development of services. Thereafter, Morelli also pointed out that PSS design methodologies should focus on the requirements for the PSS and its organizational structure, the identification of involved actors, the possible scenarios of PSS use cases and the sequences of actors' roles, as well as the representation of the PSS in all of its components (Morelli, 2006). During the same period, Aurich et al. (2006) proposed a process for the systematic design of technical PSS, which integrates product design and technical service design process. They introduced an object-oriented technical-service model to support the specification of technical service during design. Sakao and Shimomura (2007) proposed a PSS engineering methodology (process and computer-aided tools) to achieve sustainable production and consumption. This approach includes the identification of stakeholders' value and describing realization structure based on their value using the Flow Model and extended blueprint. Furthermore, Shimomura et al. (2009) developed a method for designing product and service activity collaboratively and concurrently to maximise the customer's value by mutually link service content and service activity.

More recently, the research on this topic increasingly focuses on challenges of design: (1) applicability of PSS design methodologies in an industrial context and (2) integration that covers the whole stages of the PSS design process (Cavalieri and Pezzotta, 2012). New generic design methodology as a conceptual guideline for designers is proposed to address all types of PSS (product, use or result-oriented PSS) (Tran and Park, 2014). This methodology addresses analysing the characteristic of PSS types, the design processes of products and services, stakeholder involvement and the change in business model and organization structure. Pezzotta et al. (2016) proposed a service engineering methodology composed of two areas (customer perspective and the company's internal performance) to assist companies in balancing the company's internal and external performance while PSS design. To address the abovementioned challenges, Andriankaja et al. (2018) built the PSS design method via the integration between a highly standardized product-oriented framework (functional analysis approach) and a specific PSS-oriented design approach. This integration has mediated throughout the development of the design-oriented decision-aid tool.

Whereas most extant research has focused on the generation of PSS design methodologies, there is a lack of long-term perspective for PSS to treat related risks and uncertainties. Likewise, the other life cycle phases such as implementation and monitoring are not addressed sufficiently (Cavalieri and Pezzotta, 2012; Vasantha et al., 2012). Furthermore, while several methods and tools have developed, the application of the proposed methods remain very limited (Ceschin, 2013). Therefore, recent research starts to work on methodologies and frameworks for implementation and diffusion of PSS (Ceschin, 2014; Vezzoli et al., 2016).

\subsection{The design approach for sustainability transitions}

In light of the changes in social conditions, sustainability transition is necessary to achieve a sustainable society. Sustainability transition is a transformative restructuring of a Socio-Technical System (STS) that fulfils our requirements (Geels, 2011). These transformations cover institutional, social/cultural, organizational as well as technological change (Loorbach, 2010).

(Geels, 2004, 2011) proposed the multi-level perspective (MLP) framework, which conceptualizes overall dynamic patterns in socio-technical transitions to sustainability. This framework views transitions as non-linear processes that result from the interplay of developments at three analytical levels: niches (micro), socio-technical regimes (meso) and an exogenous socio-technical landscape (macro) (Geels, 2004). The regime level is the primary level because transitions are defined as shifts from one regime to another. The niche and landscape levels can be seen as 'derived concepts' because they are defined in relation to the regime, namely as practices or technologies that deviate substantially from the existing regime and as external environments that influence interactions between niche(s) and regime (Geels, 2011).

Nevertheless, the framework continues to be a helpful analytical tool for investigating sustainability transitions. To realize the contribution to sustainability, it is essential to appropriately design and diffuse products/services to be accepted by the target system. In response to the above-mentioned requirements for sustainability transition, a new discipline, design for sustainability transition (DfST), has emergent (Gaziulusoy and Brezet, 2015; Joore and Brezet, 2015; Gaziulusoy and Öztekin, 2019). This approach regards sustainability as a moving target, which should be planned through a process-based, multi-scale 
and systemic approach. Since sustainability is a dynamic system property and not predictive, it is guided by targets/visions, instead of traditional goal-based optimization approaches (Gaziulusoy and Brezet, 2015).The DfST frameworks usually consist of four cyclic and adaptive processes: establishment of transition arena (key stakeholders network), development of long term sustainability visions and a shared transition agenda (routes to a vision via intermediate objectives), initiation of socio-technical experiments, evaluating, monitoring and learning (Vezzoli et al., 2008; Loorbach, 2010; Ceschin, 2013). To operationalize such a framework for design activities, the methodologies towards DfST have been developed. In DfST field, drawing strategic pathways for transitions is one of the major challenges. Gaziulusoy et al. (2013) has developed an operational scenario development method which enables the design and innovation team to align their design activity with unfolding sustainability transitions. Hyysalo et al. (2019) proposed transition path co-design toolset for accelerating socio-technical change with the collaboration of related actors. Meanwhile, pilot experiments and niche system implementations are also key endeavour for catalysing product/service implementation towards societal transformations. Ceschin (2014) has explored and delineated the design attitude and skills needed to support socio-technical system changes through action research, which introduce a socio-technical experiment (Sengers et al., 2019) concept from transition studies. These experiments are not simply tests made within one company laboratory, but a wider socio-technical experiment involving a broad range of stakeholders (e.g. a consortium including multiple companies, some interested users, a public authority, etc.).

\subsection{Integrating PSS design and design for sustainability transitions}

Despite the knowledge and tools accumulated on designing PSS mentioned in section 3.1, it should be underlined that there are still barriers to be addressed:

- Current PSS design researches not fully consider strategic long-term, process-based and adaptive perspectives to treat related risks and uncertainties.

- The middle and end of life cycle stages such as implementation and monitoring are not addressed sufficiently.

As a result of the above barriers, the application and diffusion of PSS for the market are still limited. On the other hand, radical innovations always immature when they enter the market because they cope with a dominant socio-technical regime (and its established and stable rules and networks of actors) (Geels, 2004). PSS is in most cases such a radical innovation because it requires a cultural shift for both the providers and customers (Mont, 2002; Baines et al., 2007). Therefore, there are still significant challenges to be faced, not only in developing the PSS concept but also in adopting the best strategy to introduce and diffuse it in the market.

To fill in this research gap, recent researches in the PSS field introducing key insights from DfST and its underlying theories (transition management, strategic niche management) (Ceschin, 2013, 2014; Joore and Brezet, 2015; Liedtke et al., 2015). Nevertheless, these integration efforts remain insufficient to address how these insights can complement and enrich the conventional PSS design process (i.e. requirement management, concept development and evaluation, detailed design, implementation and monitoring). To enhance the contribution of PSS for sustainable development, DfST approach can provide a complementary long-term and adaptive perspective to design a sustainable PSS solution.

Meanwhile, the above condition indicates that the nature of PSS is reconsidering as a socio-technical system since it involves a complex interaction between product, technologies, service (technical system), supporting value network and infrastructure (social system). Thus, this study builds a hypothesis that DfST framework is applicable for PSS design. Based on this hypothesis, this paper proposes a conceptual framework of sustainable PSS design for sustainability transition by integrating the transition management cycle and its three activity levels with the PSS design process. The next section will provide an in-depth explanation about the proposal.

\section{A conceptual framework of PSS for sustainability transitions}

This paper proposes a conceptual framework for a sustainable PSS design by integrating the insight obtained from DfST approach (Figure 1). This framework consists of four system levels and their 
relationships, as well as five design processes that should be considered in developing dependable PSSs that are accepted by STSs and contribute to sustainability. To integrate each disciplines' perspective, this study specifically refers to the system view of PSS design (Cavalieri and Pezzotta, 2012), transition management cycle (Loorbach, 2010) and critical factors for implementing and diffusing sustainable PSS (Ceschin, 2013) as a representative framework from each field. The following provides an explanation about the design activity level and system design phases in this proposal.

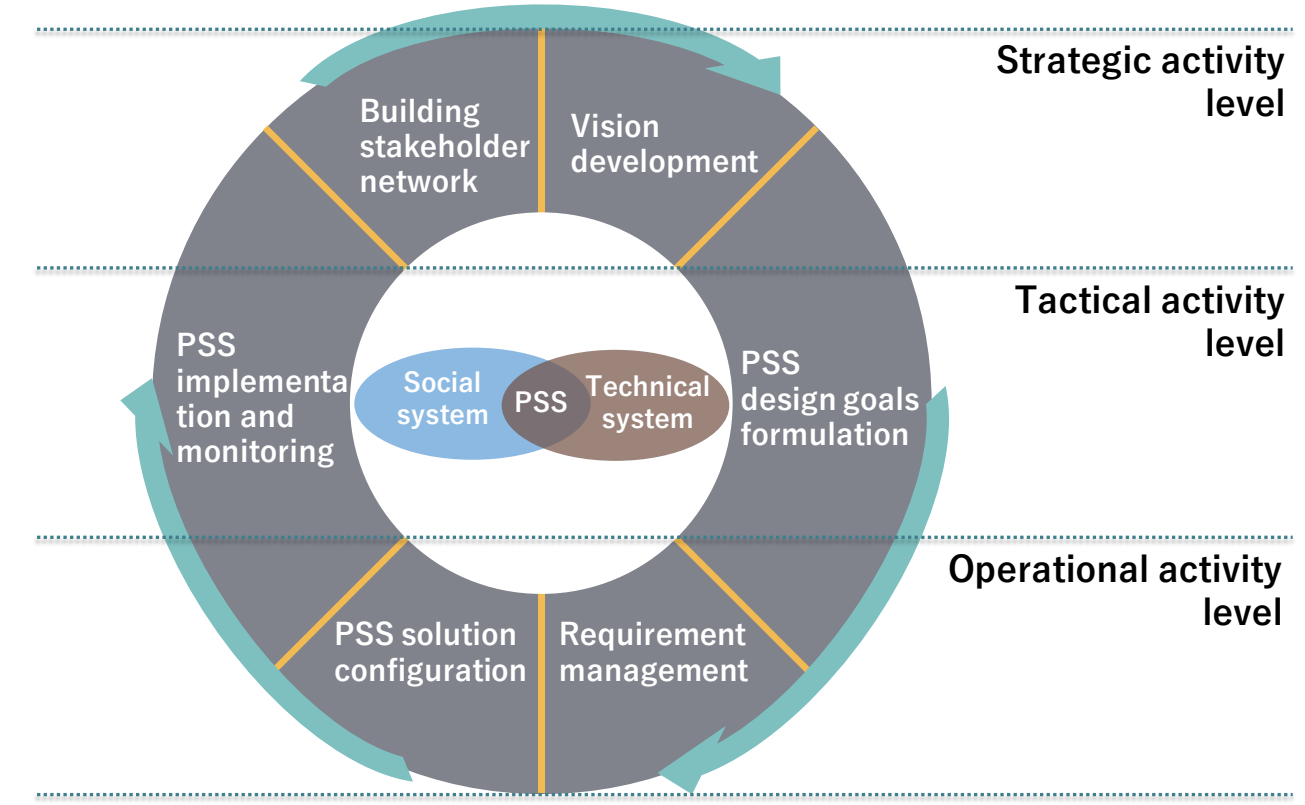

Figure 1. A conceptual framework of PSSs design for sustainability transitions

\subsection{Multiple design activity level in the framework}

The proposed framework adapts three activity levels required by sustainability transitions: (1) Strategic activities; (2) Tactical activities; (3) Operational activities (Loorbach, 2010). These activities are summarised as follows (Gaziulusoy and Ryan, 2017):

- Strategic activities involve the formation of long term goals and visions that will lead to changes in the culture and structure of a socio-technical system. The long term goals and visions should include not only new technologies, products and services but also norms and values, social identity and politico-economic model that together will enable governance of the future depicted in these visions. This focus coincides with the landscape level in the MLP framework.

- Tactical activities are directed at implementing a transition agenda towards the desired goal and relate to interactions between actors that can build and align the new vision into the regime level. This can include activities relating to changes in structures, such as investments and other resource distributions, rules, incentives, and underlying infrastructure. Negotiations regarding interests are more common in this sphere. It also involves understanding barriers/risks that may inhibit the advancement of the visions and propose adjustments that may be needed.

- Operational activities relate to the experiments and learning-by-doing at the niche level, often with an emphasis on radical and disruptive innovations that may potentially filter up into the regime and landscape level.

Conventional PSS design corresponds to operational activity level because these methodologies were developed with the intent of embedding them in designers' and engineers' day-to-day work. As mentioned in section 3.3, this study regards the nature of PSS as a socio-technical system. Thus, the proposed framework introduces strategic and tactical design level perspective. These perspectives could have a role not only in 
generating PSS concepts but also in developing diffusion planning of the concept itself considering changes/risks in its operation. In this sense, this framework can guide designers (company, an institution or a network of actors), in the process of gradually designing and implementing PSS embed in the society.

\subsection{Design phases in this framework}

Based on the integration of relevant phases from disciplines, the proposed framework consists of cyclic six design phases. The following will provide a detailed explanation of these phases.

\subsubsection{Building stakeholder network (strategic level)}

The establishment and development of a proper socio-economic network are recognised as a crucial process to protect, support and foster innovation development (Loorbach, 2010; Ceschin, 2013). As the starting point of PSS design, this phase identifies and involves actors directly or indirectly linked with the PSS development. A key element is the network of stakeholders that produce and deliver the solution to customers. Therefore, for companies that adopt a PSS-oriented approach, network building is a crucial activity (Cavalieri and Pezzotta, 2012). On the other hand, DfST-oriented approach focuses not only on the actors directly linked to the PSS (partners, suppliers, customers, etc.) but also to the actors that could provide support and protection to that solution (e.g., research centres, governmental institutions, NGOs, special interest groups, etc.). A broader system approach should be adopted by companies, in order to think to the contextual conditions that may favour the societal embedding of the PSS, and to what actors could be involved to support this process (Ceschin, 2013).

\subsubsection{Vision development (strategic level)}

The second phase develops a shared long-term vision, which gives a direction to the PSS development and involved stakeholders' actions. This vision represents what the stakeholders want to reach, a future state in which the identified deficiency of the current system was resolved by PSS. The problems recognised by stakeholders within the built network are affected by the surrounding social context (Geels, 2004). Thus, deficiency includes not only technical and organizational but also sociocultural and institutional problems. Visioning is an activity at a strategic level that used to carry out, and several tools have been developed to support a collective building and refinement of complex solutions. For instance, an important conceptual tool that is highlighted in the extant literature is the creation of "transition scenarios" which are plausible, coherent narratives of pathways that could bring about the desired future state. Transition scenarios can help engage and align stakeholders, but can also help prepare more resilient strategies by anticipating deviations from trends (Sondeijker, 2006).

\subsubsection{PSS design goals formulation (tactical level)}

PSS design goals that are intermediate objectives must be achieved through implementation. While looking at the developed vision, more specific design goals are defined by considering the resources (knowledge, technology, cost) owned by the PSS design company and the period of PSS development project, etc. Here, the design goals are described by intermediate key goal indicators (KGI) that should be achieved in order to resolve the deficiencies of function.

In addition, it is important to clarify the accountability and failure countermeasure plan during PSS operation and to build consensus within relevant stakeholders by anticipating and identifying implementation and diffusion barriers (changes and risks in PSS and its surrounding environment).

\subsubsection{Requirement management (operational level)}

This phase identifies functional/technical requirements for the PSS based on the developed design goals. This phase includes requirement generation, identification and analysis, and several methods and tools are adopted in PSS design (e.g. Quality function deployment, TRIZ, Critical incident technique) (Cavalieri and Pezzotta, 2012). This phase also requires consensus building on requirements among relevant stakeholders to validate target requirements by getting feedback from those stakeholders. Moreover, it is necessary to specify the requirements not only in terms of simply achieving the design goals but also in consideration of value-in-use (Vargo and Lusch, 2004) of PSS customers. 


\subsubsection{PSS Solution configuration (operational level)}

The identified functional/technical requirements are then translated into concrete PSS solutions that align with design goals. The PSS-oriented approach uses some techniques to generate PSS realization structure (e.g. Service modelling, Service blueprint, IDEF0, stakeholder mapping) (Morelli, 2006; Cavalieri and Pezzotta, 2012). However, since alternative PSS solutions may be developed, it is necessary to specify the optimal solution through an iterative evaluation and reconfiguration process. Therefore, this phase introduces an "experiment" concept (Ceschin, 2014; Liedtke et al., 2015; Sengers et al., 2019) to evaluate PSS solutions by involving the relevant stakeholder and assumed end-user and by setting the actual PSS usage situation. The implementation of local experiments, to test the technical, social, political and economic configuration of the innovation, and favour its societal embedding, could represent a potentially promising strategy for companies who want to shift towards a PSS oriented approach (Ceschin, 2013). Throughout introducing a PSS prototype in such an environment, it is possible to co-create solutions and evaluate the effectiveness, validity and acceptance of PSS solutions.

\subsubsection{PSS implementation and monitoring (tactical level)}

A final phase is performed for the implementation and monitoring of the PSS based on the specified PSS solution. This phase elaborates on a plan of the product development process as well as a PSS value network consolidation that includes the required partners to deliver service. Designers should also set up a plan to commercialize the PSS.

After implementing the PSS to market, each actor interacts within the network form a new PSS that is updated in institutional, socio-cultural, organizational and technical dimensions. This new PSS state is evaluated from the viewpoint of the set design goal, and the initially developed vision may need to be reconsidered depending on the result of the evaluation.

It is important to remark that the above design phases are a continuous and iterative activity along the entire PSS development process. There are cases where new failures and changes occur when the PSS is implemented. In that case, the execution of the countermeasure plan and the accountability of each stakeholder should be carried out. Then, consensus should be built again on the improvement of the PSS in order to prevent the recurrence of failures, and the continuous PSS development activities based on it will be promoted. Furthermore, designers should deal with a stakeholder network which is not static, but dynamic, because the actors and also the related interactions/relations to adapt such changes are needed to realize sustainable PSS. Therefore, the stakeholder network will evolve in time. Although it is difficult to predict the behaviour of society, it is important to endeavour to realize the sustainable PSS by continuously carrying out the above feedback and barriers handling.

\section{Simulating applicability of the proposed framework}

The proposed framework is demonstrated by using an example of PSS development project for wildlife nuisance in a suburban city in the western parts of Tokyo. Agricultural damage from wildlife such as wild boars is spreading in the urban area (Castillo-Contreras et al., 2018). As a countermeasure against this, the local government is trying to control the damage through wide-area observation by introducing fixed-point cameras. However, it has been predicted that the damage will affect humans and agriculture due to the frequent appearance of dangerous animals (Ficetola et al., 2014). To address this issue, the city needs systemic change that will not just develop technologies but also transform the lifestyle of residents, as well as the policy related to wildlife protection. With this background, this project aims to develop a PSS that suppresses severe damage caused by wildlife. The following explains the application result of the framework to the example case which simulated the applicability of the proposal as a conceptual framework.

At first, this project starts to develop a stakeholder network related to wildlife nuisance. This network including key actors from companies possessing image processing technology, local government office (planning policy section, agricultural administration section, environmental policy section), industrial technology research institute and universities.

In the vision development phase, when considering the problem of wildlife nuisance in a suburban area, the community acknowledges deficiency of function related to prevention and deterrence of wildlife nuisance arising from situations in which residents' farms are devastated by wildlife. In this 
background, there are wider problems, such as a decrease in the area where animals can live due to environmental destruction, and problems with local wildlife protection management law.

Due to the deficiency of function related to the prevention and deterrence of wildlife nuisance, it is required to realize the value of residents such as "richness by increasing agricultural profit" or "purpose of life through agriculture". Then, a vision of the city through implementing PSS - "a city that can coexist with animals"-is developed as a shared long-term vision.

Then, looking at the vision, ideas such as "development of wildlife observation system", "establishment of utilization method of acquired data from observation system", "identifying habitats and populations of wildlife by expanding the system through geographic information system integration" and "Reduce total agricultural damage $20 \%$ " are developed as immediate design goals.

When local government belonging to the target city manages and operates the wildlife observation system, even if they can suppress wildlife nuisance, it is not acceptable for the use of the system to increase the work burden and stress on the staff. As such, PSS requirements such as "Ease of operation of the observation system" are identified.

In the PSS solution configuration phase, local government officers try a prototype of the PSS in an actual business environment, so that the needs of "Reduction of management report creation burden" that have been overlooked so far are identified. As a result, the PSS solution is accordingly refined.

Finally, the wildlife observation system is developed based on a specific PSS solution idea. After it is implemented in the target city, it evaluates whether the actual reduction rate of total damage was achieved or not. As the understanding of the local wildlife ecosystem progresses, issues related to coexistence with wildlife will emerge. This may accordingly redefine the vision. Moreover, PSS implementation may cause changes in the requirement of users and emerges risks in this area. By continuously corresponding to these changes, the developed system can be a sustainable PSS.

\section{Discussion and conclusion}

There is a need for the development of PSS design methodology with a long-term perspective deal with uncertainties related to PSS and its surrounding environment. As an initial step, this paper proposed a conceptual framework of sustainable PSS design, which is developed by integrating DfST approach. The proposed framework can be expected to be used as an analytical framework for PSS design, as shown in Section 4. By illustrating this framework's applicability by using the example of PSS development, designers can acquire insights related to (a) the scale of the design activity level taken into account, (b) specific design activities performed in each phase and (c) attitude to manage the PSS development and implementation process from long-term perspective. Furthermore, through the accumulation of such applications, the proposed framework can be elaborated upon as a design guideline which organizes basic principles and practices of dependable PSS development for a sustainability transition. Thus, the proposed framework also potentially has a role for a designer as a reference model to achieve sustainability transition through PSS development.

Meanwhile, this study acknowledges some remaining issues to be addressed in future works. First, since this paper only conducted the first stage of research process presented in section 2, it is necessary to work on the development of an operational method for PSS designers. To address this issue, this study selects operational methods and tools based on the proposed framework. In PSS study, many design methods and tools are presented in existing research. From DfST approach, Project assessment framework for sustainability (Allais and Gobert, 2019) also may enrich the proposed framework in that it allows dynamic evaluation of on-going project. By investigating each study, it is possible to identify appropriate design tools for implementing each phase.

Second, the proposed framework is prescriptive and has only been applied experimentally to an example of wildlife nuisance in a suburban area. Therefore, this paper still could not provide any evidence that this design framework is an applicable, effective and useful in PSS design. In order to make this framework operational with practical PSS development, it is necessary to evaluate its versatility and completeness through application to actual PSS development cases. As a result, it is assumed that objectivity can be ensured by identifying a lack of perspective in this framework and differences from actual PSS development and improvement based on such results. However, it has to be underlined that the proposed framework is intended to be applied to particular development case of 
PSS which has socio-technical nature. Thus, this study is different from the design approach for industrial PSS development that likely focuses on business to business applications.

For the above remaining issues, future work can address the following questions: How PSS designers (not only the engineers but also related stakeholders) can operate the proposed framework? How effective, versatile, and useful is the proposed framework in actual sustainable PSS design?

These two research questions to be verified with further research and field applications.

\section{References}

Allais, R. and Gobert, J. (2019), "Conceptual framework for spatio-temporal analysis of territorial projects", Environmental Impact Assessment Review, Vol. 77 No. April, pp. 93-104, pp. 93-104. https://doi.org/ 10.1016/j.eiar.2019.03.003

Andriankaja, H., Boucher, X. and Medini, K. (2018), “A method to design integrated product-service systems based on the extended functional analysis approach", CIRP Journal of Manufacturing Science and Technology, CIRP, Vol. 21, pp. 120-139. https://doi.org/10.1016/j.cirpj.2018.02.001

Annarelli, A., Battistella, C. and Nonino, F. (2016), "Product service system: A conceptual framework from a systematic review", Journal of Cleaner Production, Vol. 139, pp. 1011-1032. https://doi.org/10.1016/ j.jclepro.2016.08.061

Aurich, J.C., Fuchs, C. and Wagenknecht, C. (2006), "Life cycle oriented design of technical Product-Service Systems", Journal of Cleaner Production, Vol. 14 No. 17, pp. 1480-1494. https://doi.org/10.1016/ j.jclepro.2006.01.019

Baines, T. et al. (2017), "Servitization: revisiting the state-of-the-art and research priorities", International Journal of Operations and Production Management, Vol. 37 No. 2, pp. 256-278. https://doi.org/10.1108/ IJOPM-06-2015-0312

Baines, T.S. et al. (2007), "State-of-the-art in product-service systems", Proceedings of the Institution of Mechanical Engineers, Part B: Journal of Engineering Manufacture, Vol. 221 No. 10, pp. 1543-1552. https://doi.org/10.1243/09544054JEM858

Brambila-Macias, S.A., Sakao, T. and Kowalkowski, C. (2018), "Bridging the gap between engineering design and marketing: insights for research and practice in product/service system design”, Design Science, Vol. 4, p. e7. https://doi.org/10.1017/dsj.2018.3

Castillo-Contreras, R. et al. (2018), "Urban wild boars prefer fragmented areas with food resources near natural corridors", Science of the Total Environment, Vol. 615, pp. 282-288. https://doi.org/10.1016/j.scitotenv. 2017.09.277

Cavalieri, S. and Pezzotta, G. (2012), "Product-service systems engineering: State of the art and research challenges", Computers in Industry, Vol. 63 No. 4, pp. 278-288. https://doi.org/10.1016/j.compind.2012. 02.006

Ceschin, F. (2013), "Critical factors for implementing and diffusing sustainable product-Service systems: Insights from innovation studies and companies' experiences", Journal of Cleaner Production, Vol. 45, pp. 74-88. https://doi.org/10.1016/j.jclepro.2012.05.034

Ceschin, F. (2014), "How the design of socio-technical experiments can enable radical changes for sustainability", International Journal of Design, Vol. 8 No. 3, pp. 1-21.

Cross, N. (2001), "Designerly Ways of Knowing: Design Discipline Versus Design Science", Design Issues, Vol. 17 No. 3,pp. 49-55. https://doi.org/10.1162/074793601750357196

Ficetola, G.F. et al. (2014), "Predicting wild boar damages to croplands in a mosaic of agricultural and natural areas”, Current Zoology, Vol. 60 No. 2, pp. 170-179. https://doi.org/10.1093/czoolo/60.2.170.

Gaziulusoy, A.I. and Brezet, H. (2015), "Design for system innovations and transitions: A conceptual framework integrating insights from sustainablity science and theories of system innovations and transitions", Journal of Cleaner Production, Vol. 108, pp. 558-568. https://doi.org/10.1016/j.jclepro.2015.06.066

Gaziulusoy, A.I. and Ryan, C. (2017), "Roles of design in sustainability transitions projects: A case study of Visions and Pathways 2040 project from Australia", Journal of Cleaner Production, Vol. 162, pp. 12971307. https://doi.org/10.1016/j.jclepro.2017.06.122

Gaziulusoy, A.I., Boyle, C. and McDowall, R. (2013), "System innovation for sustainability: A systemic doubleflow scenario method for companies", Journal of Cleaner Production, Vol. 45, pp. 104-116. https://doi.org/10.1016/j.jclepro.2012.05.013

Gaziulusoy, A.I. and Öztekin, E.E. (2019), "Design for sustainability transitions: Origins, attitudes and future directions", Sustainability (Switzerland), Vol. 11, p. 13. https://doi.org/10.3390/su11133601

Geels, F.W. (2004), "From sectoral systems of innovation to socio-technical systems: Insights about dynamics and change from sociology and institutional theory", Research Policy, Vol. 33 No. 6-7, pp. 897-920. https://doi.org/10.1016/j.respol.2004.01.015 
Geels, F.W. (2011), "The multi-level perspective on sustainability transitions: Responses to seven criticisms", Environmental Innovation and Societal Transitions, Vol. 1 No. 1, pp. 24-40. https://doi.org/10.1016/j.eist. 2011.02.002

Hevner, M. and Ram, P.a. (2004), "Design Science in Information Systems Research”, MIS Quarterly, Vol. 28 No. 1, p. 75. https://doi.org/10.2307/25148625

Hyysalo, S. et al. (2019), "Codesign for transitions governance: A Mid-range pathway creation toolset for accelerating sociotechnical change", Design Studies, Vol. 63, pp. 181-203. https://doi.org/10.1016/j.destud. 2019.05.002

Joore, P. and Brezet, H. (2015), “A Multilevel Design Model: The mutual relationship between product-service system development and societal change processes", Journal of Cleaner Production, Vol. 97, pp. 92-105. https://doi.org/10.1016/j.jclepro.2014.06.043

Ledford, H. (2015), "How to solve the world's biggest problems", Nature, Vol. 525, pp. 308-311. https://doi.org/ $10.1038 / 525308 \mathrm{a}$

Liedtke, C. et al. (2015), "User-integrated innovation in Sustainable LivingLabs: An experimental infrastructure for researching and developing sustainable product service systems", Journal of Cleaner Production, Vol. 97, pp. 106-116. https://doi.org/10.1016/j.jclepro.2014.04.070

Loorbach, D. (2010), "Transition Management for Sustainable Development: A Prescriptive, Complexity-Based Governance Framework", Governance, Vol. 23 No. 1, pp. 161-183. https://doi.org/10.1111/j.1468-0491. 2009.01471.x

Mont, O. (2002), "Clarifying the concept of product-service system", Journal of Cleaner Production, Vol. 10 No. 3, pp. 237-245. https://doi.org/10.1016/S0959-6526(01)00039-7

Morelli, N. (2003), "Product-service systems, a perspective shift for designers: A case study - The design of a telecentre", Design Studies, Vol. 24 No. 1, pp. 73-99. https://doi.org/10.1016/S0142-694X(02)00029-7.

Morelli, N. (2006), "Developing new product service systems (PSS): methodologies and operational tools", Journal of Cleaner Production, Vol. 14 No. 17, pp. 1495-1501. https://doi.org/10.1016/j.jclepro.2006. 01.023

Pezzotta, G. et al. (2016), "Towards a methodology to engineer industrial product-service system - Evidence from power and automation industry", CIRP Journal of Manufacturing Science and Technology, Vol. 15, pp. 19-32. https://doi.org/10.1016/j.cirpj.2016.04.006

Rittel, H.W.J. and Webber, M.M. (1973), "Dilemmas in a General Theory of Planning”, Policy Sciences, Vol. 4 No. 2, pp. 155-169. https://doi.org/10.1007/BF01405730

Sakao, T. and Shimomura, Y. (2007), "Service Engineering: a novel engineering discipline for producers to increase value combining service and product", Journal of Cleaner Production, Vol. 15 No. 6, pp. 590-604. https://doi.org/10.1016/j.jclepro.2006.05.015

Sengers, F., Wieczorek, A.J. and Raven, R. (2019), "Experimenting for sustainability transitions: A systematic literature review", Technological Forecasting and Social Change, Vol. 145, pp. 153-164. https://doi.org/ 10.1016/j.techfore.2016.08.031

Shimomura, Y., Hara, T. and Arai, T. (2009), "A unified representation scheme for effective PSS development", CIRP Annals - Manufacturing Technology, Vol. 58 No. 1, pp. 379-382. https://doi.org/10.1016/j.cirp.2009. 03.025

Sondeijker, S. et al. (2006), "Imagining sustainability: The added value of transition scenarios in transition management", Foresight, Vol. 8 No. 5, pp. 15-30. https://doi.org/10.1108/14636680610703063

Tran, T.A. and Park, J.Y. (2014), "Development of integrated design methodology for various types of product - service systems", Journal of Computational Design and Engineering, Vol. 1 No. 1, pp. 37-47. https://doi.org/10.7315/JCDE.2014.004

Vargo, S.L. and Lusch, R.F. (2004), "Evolving to a New Dominant Logic for Marketing", Journal of Marketing, Vol. 68 No. 1, pp. 1-17. https://doi.org/10.1509/jmkg.68.1.1.24036

Vasantha, G. et al. (2012), "A review of product-service systems design methodologies", Journal of Engineering Design, Vol. 23 No. 9, pp. 635-659. https://doi.org/10.1080/09544828.2011.639712

Vezzoli, C., Ceschin, F. and Kemp, R. (2008), "Designing transition paths for the diffusion of sustainable system innovations", Proceedings of Changing the Change - an International Conference on the Role and Potential of Design Research in the Transition towards Sustainability, Turin, Italy, July 10-12, 2008, Allemandi, Turin, pp. 1-14.

Vezzoli, C. et al. (2016), "New design challenges to widely implement "Sustainable Product-Service Systems"”, Journal of Cleaner Production, Vol. 97, pp. 1-12. https://doi.org/10.1016/j.jclepro.2015.02.061 